\title{
LETTERS
}

\section{Letter to the editor: HIV-1 outbreak among injecting drug users in Greece, 2011: a preliminary report}

Mika Salminen (mika.salminen@ecdc.europa.eu) ${ }^{1}$

1. European Centre for Disease Prevention and Control (ECDC), Stockholm, Sweden

Citation style for this article:

Salminen M. Letter to the editor: HIV-1 outbreak among injecting drug users in Greece, 2011: a preliminary report.

Euro Surveill. 2011;16(41):pii=19986. Available online: http://www.eurosurveillance.org/ViewArticle.aspx?Articleld=19986

Article published on 13 October 2011

To the editor: I read with great interest the article by Paraskevis et al. on the approximately 10 -fold increase in reported cases of HIV-1 among injecting drug users (IDUs) in Greece, recently published in Eurosurveillance [1]. The authors conclude that the increase reflects a recent outbreak among users. They use data collected through the systematic case reporting surveillance system and specialised laboratory studies (mainly sequencing based cluster or phylogenetic analysis) to further suggest that the root cause of the outbreak is transmission from HIV-positive migrants to native Greek drug users.

The conclusions of the study could be interpreted as suggesting that migration constitutes an external threat to the health of the native population. I think that this is an over-interpretation of the results. Such over-interpretation is not uncommon to epidemiological studies primarily reliant on high-resolution molecular typing, often also called molecular epidemiological studies.

High-resolution molecular typing relies on the sequencing and comparison of parts of or entire genomes of microbes. It allows classification of a microbial isolate or sample sequence according to its genetic relatedness to sets of potentially related sequences stored in research or reference databases. While the approach has potential for epidemiological analysis, it also has several limitations, insufficiently discussed in the report by Paraskevis et al. A thorough discussion of these limitations would be necessary and further research on the value of high-resolution typing for epidemiological studies is still needed.

Paraskevis et al. have compared HIV sequences sampled from newly reported cases among IDUs to sequences isolated from HIV cases in Greece in a large database $(n=2,337)$, which were collected mainly through analyses of HIV drug resistance for clinical monitoring [2]. While relatively large, the representativeness of this database in relation to the HIV epidemic in Greece is difficult to assess. Furthermore, data collected through clinical monitoring are usually under-represented for IDUs.

The data that the authors show are not described in a way that would demonstrate representativeness of the sampled population (IDUs in Greece). The analysis is based on a total of 34 cases and only limited sociodemographic data are shown for the cases analysed and none for the reference population (the large database of sequences) it is compared with. Biased inclusion of cases in the reference database could easily result in masking an existing epidemic and enhanced sampling due to rising awareness could result in a false impression of a 'new' outbreak.

The authors state that: 'This finding supports a recent introduction from migrating population [...] and 'viral sources for the different networks were mainly originated from globally circulating viruses (CRF14_BG, subtype A) suggesting a potential role of migrant IDUs for the initiation of the recent outbreak'. While the authors acknowledge that another interpretation is possible, the conclusion that the outbreak was of migrant origin is reiterated as the main finding. Examination of the phylogenies presented in the report shows that there have been multiple introductions of HIV and sub-epidemics among IDUs in Greece in the past and this is evident even in the sample set analysed for this study. The authors miss the most important public health message highlighted by the outbreak: that the risks of HIV transmission by injecting drug use have not been properly addressed through prevention and therefore an outbreak was possible. The message should be that the prevention programme for this vulnerable group has failed.

From a prevention perspective, the origin of the outbreak virus (or its host) makes little difference and is likely to be a stochastic event that has mainly an academic interest. Prior examples of such stochastic events are common among IDUs [3, 4]. It is obviously important not to stigmatise migrants as being responsible for an HIV epidemic among IDUs, rather, it 
is important to identify risks and then take appropriate preventive public health action. As pointed out by the authors, there is a need for an integrated and combined prevention initiative addressing infection risks among IDUs as a response to the increasing number of HIV cases in this vulnerable group.

\section{References}

1. Paraskevis D, Nikolopoulos G, Tsiara C, Paraskeva D, Antoniadou A, Lazanas M, et al. HIV-1 outbreak among injecting drug users in Greece, 2011: a preliminary report. Euro Surveill. 2011;16(36):pii=19962. Available from: http://www. eurosurveillance.org/ViewArticle.aspx?Articleld=19962

2. Paraskevis D M, Zavitsanou E, Detsika A, Magiorkinis $M$, Papa G, Beloukas A, et al for the multicenter study of HIV heterogeneity (2010). Molecular typing of the HIV-1 networks through a nationwide study in Greece: predominance of subtype A over B spreading among the natives. 10th International Conference on Molecular Epidemiology and Evolutionary Genetics of Infectious Diseases Amsterdam. 3-5 Nov 2010.

3. Zetterberg V, Ustina V, Liitsola K, Zilmer K, Kalikova N, Sevastianova K, et al. Two Viral Strains and a Possible Novel Recombinant are Responsible for the Injecting Drug Use-Associated HIV-epidemic in Estonia. AIDS Res Hum Retroviruses. 2004;20(11):1148-56.

4. Liitsola K, Ristola M, Holmström P, Salminen M, BrummerKorvenkontio H, Simola S, et al. An outbreak of the circulating recombinant form AECM240 HIV-1 in the Finnish injection drug user population. AIDS. 2000;14(16):2613-5. 